\title{
Advocating for LGBTQ+ Students with Disabilities
}

\author{
June Gothberg, Western Michigan University \\ LaSonja Roberts, Western Michigan University \\ Mary Ebejer, Western Michigan University
}

June Gothberg is an Assistant Professor at Western Michigan University. Her research-to-practice work focuses on supporting young people with unique abilities and life experiences. When June is not teaching graduate level research methods, she is federally-funded to support state and local education, rehabilitation, and correctional agencies to improve outcomes for children with disabilities, court-involved youth, and others at-risk.

LaSonja Roberts is an Assistant Professor at Western Michigan University in the Educational Leadership Research and Technology Department. Her research agenda focuses on leader preparation and retention, specifically a leader's ability to create environments that foster the learning and well-being of educators and students. LaSonja has had the privilege to teach and lead in California, Mississippi, and Florida.

Mary Ebejer is a Faculty Specialist at Western Michigan University. As the graduate writing coach for the College of Education and Human Development, her work focuses on providing much-needed writing and self-efficacy support to students from all backgrounds, but particularly non-traditional students, international students, and those from other marginalized communities, as they pursue their masters and doctoral degrees.

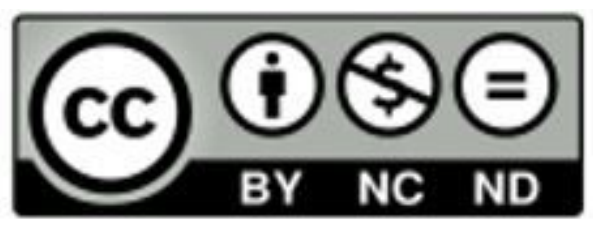

See: https://creativecommons.org/licenses/by-nc-nd/2.0/ 


\begin{abstract}
Summary
Much of education research in recent years has focused on how the bullying and victimization of LGBTQ+ students and youth with disabilities (YWD) can lead to increased challenges and limited opportunities later in life. However, few studies have focused on how bullying and victimization affects students who both have disabilities and identify as LGBTQ+ or on how specific practices could improve both their experiences in school and their success later in life. YWD face the same challenges when it comes to puberty, social identity, and planning for adult roles as their non-disabled peers, but they are more likely to struggle with developing their identity and thinking about their future, particularly if they identify as LGBTQ+, which is why educators and parents must work together to advocate for changes that promote an inclusive, safe, and just environment for all students. In this article, we offer guidance using evidence-based promising practices (EBPPs) to improve educational settings for LGBTQ+ YWD that is informed by our work at the state, local, and classroom levels.
\end{abstract}

Intended Audience: K-12 Educators and Parents

Keywords: advocacy, curriculum, disability, LGBTQ+, sexuality 


\title{
Advocating for LGBTQ+ Students with Disabilities
}

\author{
June Gothberg, Western Michigan University \\ LaSonja Roberts, Western Michigan University \\ Mary Ebejer, Western Michigan University
}

Adolescents typically face challenges when it comes to puberty, social identity, and planning for adulthood. Youth with disabilities (YWD), however, are more likely to struggle than their peers without disabilities (Ferri \& Connor, 2010), as these relatively routine developmental challenges may become major obstacles that can lead to low self-esteem, low self-definition, and a limited vision of their future (Ferri \& Connor, 2010; Kortering, Braziel, \& McClannon, 2010). Their confusion is confounded by a society that promotes stereotypes of heterosexual or asexual identities, leaving YWD sexuality largely unaddressed (Burr, 2015; das Nair \& Butler, 2012; East $\&$ Orchard, 2014) and difficult to understand as they transition into adulthood (Sinclair, Unruh, Lindstrom, \& Scanlon, 2015).

The confusion that YWD face is further confounded for those who also identify as LGBTQ+. While positive school experiences have grown for LGBTQ+ youth through initiatives (e.g., Gay Straight Alliance, It Gets Better Project, and The Trevor Project), students with the dual identity of LGBTQ+ YWD struggle to feel accepted and comfortable among their LGBTQ+ or any other peers (Morgan, Mancl, Kaffar, \& Ferreira, 2011). So, while LGBTQ+ YWD may have similar academic needs as their YWD peers (Dykes \& Thomas, 2015), they have unique unmet social-emotional needs that can leave them feeling socially isolated (Arrieta \& Palladino, 2014). These unmet needs are why educators and families must advocate for LGBTQ+ YWD - honoring their stated needs without judgment — so they can lead full and inclusive lives in safe and just environments.

Given the complexity of living and learning with intersectional identities, we have found in our work that for true improvement to happen, capacity must be built at the federal, state, school, and classroom levels, as well as in the home, and must begin with asking students what they need to feel safe, honored, and included. We offer the following guidance to improve educational settings for LGBTQ + YWD from over 20 years of work as a technical assistance provider, teacher, principal, and parent of an LGBTQ+ child with a disability.

\section{State and Local Policies and Planning}

Policy change and action planning are core aspects of advocacy and can significantly increase outcomes for all YWD (Kohler, Gothberg, Fowler, \& Coyle, 2016; Test, 2016; Test et al., 2009). Examples of supportive policies at the state and local levels are: (a) anti-bullying 
policies, (b) age-appropriate, comprehensive, anti-oppressive curriculum that includes sexuality education, and (c) anti-discriminatory recruitment and hiring practices that prioritize hiring diverse staff, including LGBTQ+ and persons with disabilities. Anti-bullying and harassment policies are especially critical for ensuring safe school environments. The National School Climate Survey found that nearly $60 \%$ of LGBTQ+ students, a disproportionate number, felt unsafe at school, with almost 100\% hearing anti-LGBTQ+ remarks at school (Kosciw, Greytak, Zongrone, Clark, \& Truong, 2018). Inclusive policies are necessary to help combat these realities.

Sex education policies differ from state to state (see National Conference of State Legislatures's State Policies on Sex Education in Schools). Two states, however, have taken a stand for LGBTQ+ and disability inclusive education. California adopted Seth's Law in response to a 13-year-old student taking his life. Each district is now required to adopt a policy that prohibits discrimination, harassment, intimidation, and bullying with the law mandating intervention (CA Education Code Section 234.1(b)(1)). Additionally, California curriculum honors the contributions of LGBTQ+ people in all areas of study (see California Safe Schools). New Jersey mandates that all school districts include instruction and curriculum materials that teach students about the political, economic, and social contributions of LGBTQ+ people and individuals with disabilities (Scragg, 2019). These state-level policies are important because access to inclusive curriculum correlates with higher engagement rates and lower dropout rates for both students who identify as LGBTQ+ and YWD (see The School Completion Toolkit).

Oftentimes, even education leaders with the best intentions don't know how to design, plan, and implement strategies to address the needs of LGBTQ+ YWD (Kohler \& Coyle, 2012; Kohler \& Gothberg, 2016). Breitrose (2018) offers The Community Toolbox

to assist planning for advocacy efforts. Practices to implement can be found in the Taxonomy for Transition Programming 2.0 (Kohler et al., 2016), Sexuality in Transition Planning (Stevenson, 2015), and Evidence-Based Practices across the Lifespan (Gothberg, Stegenga, \& Cate, 2016). 


\section{Figure 1. An overview of The Taxonomy for Transition Programming 2.0.}
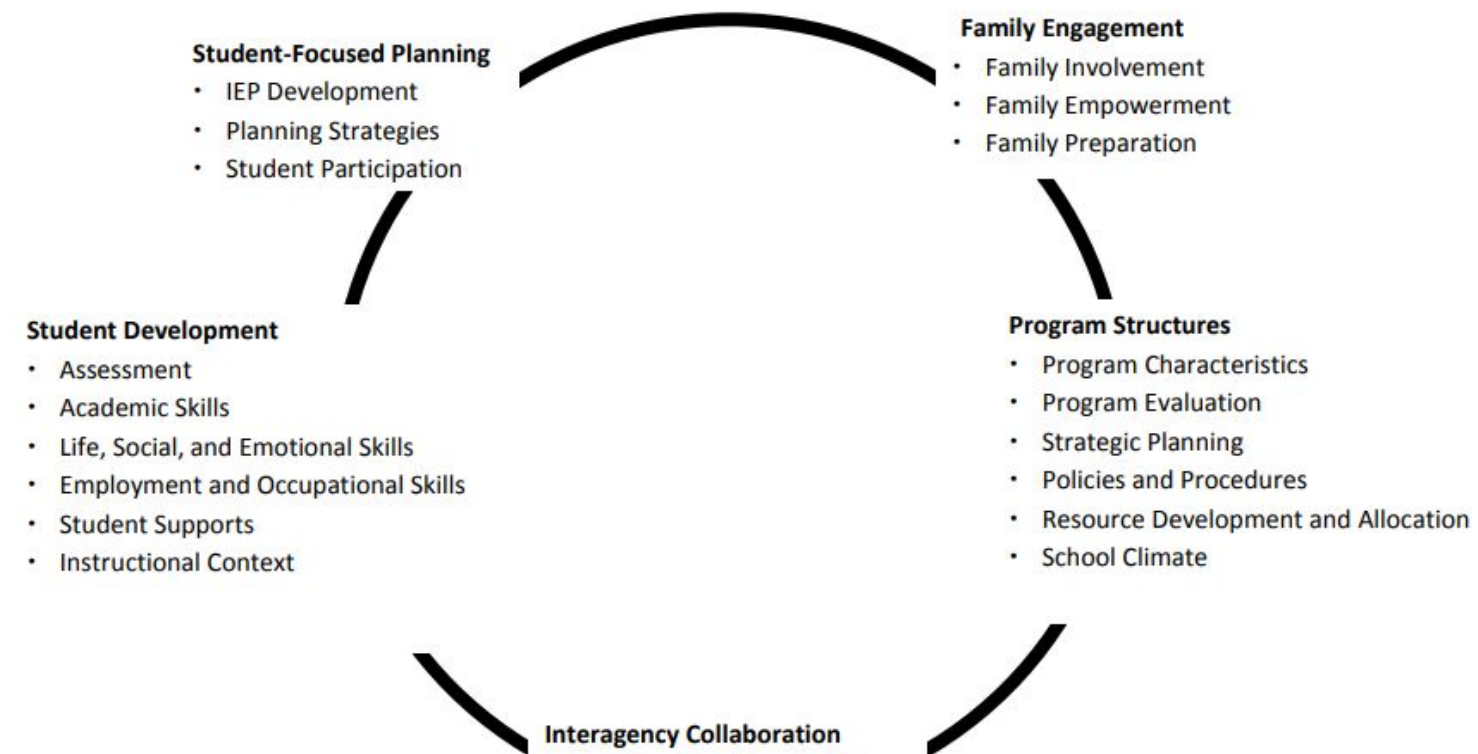

Interagency Collaboration

- Collaborative Framework

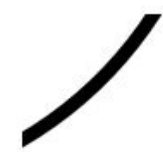

- Collaborative Service Delivery

Figure 2. School climate practices as seen in The Taxonomy for Transition Programming 2.0. 


\begin{tabular}{|l|}
\multicolumn{1}{c|}{ School Climate } \\
. School climate supports a sense of trust and \\
fairness \\
School has a clearly defined set of expectations, \\
procedures for teaching expectations, and \\
procedures for encouraging expected and school- \\
appropriate behavior \\
Programs implemented to improve students' \\
classroom behavior and social skills \\
Students are provided a personalized learning \\
environment and instructional process \\
School climate is welcoming to students, families, \\
staff, and other stakeholders \\
School climate provides a safe and nurturing \\
environment for students and adults to feel \\
connected to the school (safe from physical or \\
emotional harm, respect for diversity, fair and \\
supportive practices) \\
Environment is culturally responsive to students, \\
families, staff, and other stakeholders \\
Students' sense of engagement and belonging in \\
school is monitored \\
Staff and students interact outside the classroom \\
Adult advocates are assigned to students \\
identified as at risk of dropping out
\end{tabular}

\section{Welcoming and Inclusive Schools}

At the school level, we can help build a welcoming and inclusive climate for all students by including books and resources highlighting LGBTQ+ people with disabilities. This curriculum should focus on experiences and accomplishments throughout the school curriculum, so their portrayals aren't limited to their sexual identity or disability. This helps students feel a sense of membership and belonging in their school and community (Burke, Johnston, \& Ward, 2017). Inclusive curriculum also promotes social justice, and validates and promotes acceptance of their experiences when they see themselves reflected in texts they read (Dodge \& Crutcher, 2015).

While resources are available for elementary school (e.g., FlynntheCat1, 2012; Ryan \& Hermann-Wilmarth, 2018; Welcoming Schools, 2019), middle school (e.g., Stepaniuk, 2017), high school (e.g., Razi, 2017) and postsecondary (e.g., Cat \& Cress, 2012; Schur \& French, n.d.) students, more are needed. With resources in hand, educators must consider the best way to provide sex education curriculum to LGBTQ + YWD, given that sex education often excludes disabilities. Several resources can assist with embedding sex education holistically, specifically, and authentically (e.g., AMAZE, 2019; GenderSpectrum, 2019; Stangle, 2019).

The strongest predictor for positive outcomes for LGBTQ+ YWD is having supportive educators in their lives (Richmond, 2012). Modeling inclusive language and addressing LGBTQ+ YWD students by their chosen pronouns is one way to show respect for their identity. In addition, a report by the U.S. Department of Education (2016) found that policies that encourage safe, inclusive, and authentic learning from adults who reflect the diversity of students 
are more likely to influence environments where all students thrive. Unfortunately, discrimination and fear still exist, as seen in the harassment and eventual firing of Brett Bigham, the 2104 Oregon Teacher of the Year, after he came out at a public event (Maxwell, 2016). So bear in mind, the recruitment, hiring, and respectful inclusion of a diverse staff are an explicit display of a school's values, one that speaks volumes to students who are struggling with their own sexual identity.

\section{Principal and Teacher Preparation}

Educators tell us they feel underprepared to support either LGBTQ+ students or YWD, and that preparation programs may inadvertently perpetuate discrimination and homophobia by ignoring LGBTQ+ topics and concerns (Gorsky, Davis, \& Reiter, 2011). There is also a lack of training in principal preparation programs related to LGBTQ+ advocacy, including social justice programs (O’Malley \& Capper, 2015). So, while teachers and principals are in a unique position to dampen the effects of negative school environments, they are rarely provided the support and strategies needed to do so (Gorsky et al., 2011). Therefore, professional development is needed that specifically addresses LGBTQ+ YWD, especially in the general education setting. This could provide educators with (a) knowledge of self, beliefs, and bias, with an awareness of how they shape their students' experiences and (b) knowledge about the LGBTQ+ YWD community. Professional development should start with understanding the preferred language used to identify the group, and extend to how to creating a safe and inclusive culture.

The Anti-Defamation League (ADL) offers free anti-bias teaching resources, such as $\underline{A}$ Classroom of Difference, which focuses on inclusion and school climate by addressing issues of bias and bullying at the student, family, and educator levels. Key lesson plans include Caitlyn Jenner and The Power of Coming Out (ADL, 2015) and The Sound of Silence in Football: Derrick Coleman (ADL, 2014). The American Civil Liberties Union (ACLU) also provides free resources for activism, including the Transgender Youth Know Your Rights card that addresses respect, pronouns, restrooms, and more (ACLU, 2014). Lee Airton also offers resources including (a) They Is My Pronoun (2016) and (b) Gender: Your Guide (2018).

\section{Empowering Students at School}

Self-determination/self-advocacy is one of the 14 evidence-based predictors of post-school success (Gothberg, Stegenga, \& Cate, 2017; Test et al., 2009) and factors into students' postsecondary success (Field \& Parker, 2017). Empowering LGBTQ+ YWD with the skills needed to navigate in and outside of school successfully will help create a pathway to success throughout their lives. The school's approach to inclusive policies, culture, curriculum, and language will influence their success. Just as policies are implemented to support gender neutral bathrooms and GSAs, policies are needed to ensure the privacy and confidentiality of all students regarding their sexual orientation or gender. It is also important that there are safeguards for this information so that it is not shared without the student's permission. One example is Michigan's 
State Board of Education Statement and Guidance on Safe and Supportive Learning

Environments for $L G B T Q+$ Students, which addresses the behaviors of teachers, counselors, nurses, and all others with access to student records.

\section{Empowering Families at Home}

Families are often the best advocates for their children (Trusty \& Brown, 2005), so family acceptance is critical for all youth, and LGBTQ+ youth, in particular. Family acceptance is also one of the strongest predictors of their mental and physical well-being outcomes (McCormick \& Baldridge, 2019). So, families need to know where their child is developmentally and provide the necessary resources at the appropriate time (Wilke \& Wilke, 2010). They need to gain an understanding of state laws and school policies that affect their LGBTQ+ and/or YWD (National Conference of State Legislatures, 2019) and advocate for them when necessary. When families fail to accept or advocate for their child, the confidence and support of an advocate at school becomes critically important.

Our educational system and our nation are best served by being representative of the vast diversity of the American people (American Federation of Teachers, 2013), so all youth feel safe and welcome. Yet, many LGBTQ+ staff and students still experience the negative impacts associated with homophobia, discrimination, and perceived or actual threats to their physical safety (American Federation of Teachers, 2013). If the lives of our LGBTQ+ YWD are to improve, policy makers, educators and families need to work together as partners in this fight for equity - and the conversation should include the voices of these uniquely vulnerable students - because, in America, every young person regardless of race, ethnicity, sexual orientation, or ability should have an opportunity to a free appropriate public education and to prepare for a future of their choosing. 


\section{References}

Airton, L. (2016). They Is My Pronoun. Retrieved from https://theyismypronoun.wordpress.com/author/leeairton.

Airton, L. (2018). Gender: Your Guide. Avon, MA: Simon and Schuster.

AMAZE (2019). Disability and sexuality [video]. Retrieved from https://amaze.org/video/puberty-disability-sexuality/\#.

American Civil Liberties Union (2014). Transgender Youth Know Your Rights card. Retrieved from

https://www.aclusocal.org/sites/default/files/wp-content/uploads/2014/09/transgender-yo uth-KYR-card-Aug-2014-WEB.pdf.

American Federation of Teachers (2013). Creating a positive work environment for LGBT faculty: What higher education unions can do. Washington D.C. Retrieved from https://www.aft.org/sites/default/files/wysiwyg/genderdiversity_lgbt0413.pdf.

Anti-Defamation League (2014). The sound of silence in football: Derrick Coleman. Retrieved from

https://www.adl.org/education/educator-resources/lesson-plans/the-sound-of-silence-in-fo otball-derrick-coleman.

Anti-Defamation League (2015). Caitlyn Jenner and the power of coming out. Retrieved from https://www.adl.org/education/educator-resources/lesson-plans/caitlyn-jenner-and-the-po wer-of-coming-out.

Arrieta, S. A., \& Palladino, J. M. (2014). Special education teachers' perceptions of students with emotional impairments and their same sex behaviors: A multiple case study. Ypsilanti, MI: Eastern Michigan University Center for the Study of Equality and Human Rights.

Breitrose, P. (2018). Getting an advocacy campaign off the group. The Community Toolbox. Lawrence, K: University of Kansas.

Burke, A., Johnston, I., \& Ward, A. (2017). Challenging Stories: Literature for Social Justice in the Classroom. Toronto, Canada: Canadian Scholars' Press.

Burr, V. (2015). Social constructionism ( $3^{\text {rd }}$ ed.). New York, NY: Routledge. https://doi.org/10.4324/9781315715421

Cat \& Cress (2012). Books about lesbians with physical disabilities. Good Lesbian Books. Retrieved from http://www.goodlesbianbooks.com/2012/07/books-about-lesbians-with-physical.html.

das Nair, R., \& Butler, C. (Eds.). (2012). Intersectionality, sexuality and psychological therapies: Working with lesbian, gay and bisexual diversity. West Sussex, U.K.: John Wiley \& Sons. https://doi.org/10.1002/9781119967613

Dodge, A. M. \& Crutcher, P. A. (2015). Inclusive classrooms for LGBTQ+ students. Journal of Adolescent \& Adult Literacy, 59(1), 95-105. https://doi.org/10.1002/jaal.433 
Dykes, F., \& Thomas, S. (2015). Meeting the needs of the hidden minority: Transition planning tips for LGBTQ+ youth. Preventing School Failure, 59(3), 179-185. https://doi.org/10.1080/1045988X.2014.903462

East, L. J., \& Orchard, T. R. (2014). Somebody else's job: Experiences of sex education among health professionals, parents and adolescents with physical disabilities in southwestern Ontario. Sexuality and Disability, 32, 335-350. https://doi:10.1007/s11195-013-9289-5

Ferri, B. A., \& Connor, D. J. (2010). "I was the special ed. girl”: Urban working-class young women of color. Gender and Education, 22(1), 105-121. https://doi.org/10.1080/09540250802612688

Field, S., \& Parker, D. (2017). Becoming self-determined: Creating thoughtful learners in a standards-driven, admissions-frenzied culture. Huntersville, NC: AHEAD.

FlynntheCat1 (2012). Picture books about gay and lesbian families [blog]. Retrieved from https://hubpages.com/literature/gay-picture-books.

GenderSpectrum (2019). Principles of gender-inclusive puberty and health education. Retrieved from https://www.genderspectrum.org/staging/wp-content/uploads/2019/02/GenderSpectrum _ 2019_report_WEB_final.pdf.

Gorsky, P. C., Davis, S. N., \& Reiter, A. (2011). Heterosexism, homophobia, and other LGBTQ+ concerns in U.S. multicultural teacher education coursework. Journal of LGBT Youth, 10, 224-248. https://doi.org/10.1080/19361653.2013.798986

Gothberg, J., Stegenga, S., \& Cate, D. (2016). Evidence-based Practices Across the Lifespan. Kalamazoo, MI: Western Michigan University.

Gothberg, J., Stegenga, S., \& Cate, D. (2017). Rethinking the Paradigm. In A. L. Ellis (Ed.), Transitioning Children with Disabilities (pp. 129-144). Rotterdam, NY: Sense Publishers. https://doi.org/10.1007/978-94-6351-134-6_9

Kohler, P. \& Coyle, J. (2012). NSTTAC Transition Institute Toolkit. Kalamazoo, MI: Western Michigan University.

Kohler, P. \& Gothberg, J. (2016). NTACT Evaluation Toolkit. Kalamazoo, MI: Western Michigan University.

Kohler, P. \& Gothberg, J., Fowler, C., \& Coyle, J. (2016). Taxonomy for Transition Planning 2.0. Kalamazoo, MI: Western Michigan University.

Kortering, L. J., Braziel, P. M., \& McClannon, T. W. (2010). Career ambitions: A comparison of youth with and without SLD. Remedial and Special Education, 31(4), 230-240. https://doi.org/ 10.1177/0741932508324404

Kosciw, J. G., Greytak, E. A., Zongrone, A. D., Clark, C. M., \& Truong, N. L. (2018). The 2017 National School Climate Survey: The Experiences of Lesbian, Gay, Bisexual, Transgender, and Queer Youth in Our Nation's Schools. Gay, Lesbian and Straight Education Network (GLSEN). New York, NY 10001. 
McCormick A., \& Baldridge, S. (2019). Family acceptance and faith: Understanding the acceptance processes of parents of LGBTQ youth. Social Work \& Christianity, 46, 32-40.

Maxwell, C. (2016, July 5). Award-winning teacher talks settlement: White House visit. Windy City Times. Retrieved from http://www.windycitymediagroup.com/lgbt/Award-winning-teacher-talks-settlement-Whi te-House-visit/55762.html.

Morgan, J. J., Mancl, D. B., Kaffar, B. J., \& Ferreira, D. (2011). Creating sage environments for YWD who identify as Lesbian, Gay, Bisexual, or Transgender. Intervention School and Clinic, 47, 3-13. https://doi.org/10.1177/1053451211406546

National Conference of State Legislatures (2019). State Policies on Sex Education in Schools. Retrieved from http://www.ncsl.org/research/health/state-policies-on-sex-education-in-schools.aspx.

O’Malley, M. P., \& Capper, C. A. (2015). A measure of the quality of educational leadership programs for social justice: Integrating LGBTIQ identities into principal preparation. Educational Administration Quarterly, 51(2), 290-330. https://doi.org/10.1177/0013161X14532468

Razi, A. (2017). Recommended books with disabled main characters. Queer Books for Teens. Retrieved from http://queerbooksforteens.com/best-of-lists/books-with-disabled-main-characters.

Richmond, P. (2012). Almost Invisible: Representation of LGBT Students in Special Education Settings (Doctoral dissertation, University of Washington).

Ryan, C. L., \& Hermann-Wilmarth, J. M. (2018). Reading the rainbow: LGBTQ+-inclusive literacy instruction in the elementary classroom. New York: Teachers College Press.

Schur, D. \& French, R. (n.d.). Disability and GLBT resources. San Francisco, CA: Benchmark Institute. Retrieved from http://www.benchmarkinstitute.org/glbt/disability-and-glbt-resources.htm.

Scragg, S. (2019, Feb. 4). New Jersey governor signs bill approving LGBT-inclusive school curriculum. TAPintoNewark. Retrieved from https://www.tapinto.net/towns/newark/articles/new-jersey-governor-signs-bill-approvinglgbt-inclusive-school-curriculum-19.

Sinclair, J., Unruh, D., Lindstrom, L., \& Scanlon, D. (2015). Barriers to sexuality for individuals with intellectual and developmental disabilities: A literature review. Education and Training in Autism and Developmental Disabilities, 50, 3-16. Retrieved from http://daddcec.org/Portals/0/CEC/Autism_Disabilities/Research/Publications/Education Training_Development_Disabilities/Full_Journals/ETADD_50(1)_3-16.pdf

Stepaniuk, C. (2017, May 5). 14 more LGBTQ+ middle grade books. BookRiot. https://doi.org/10.5860/cal.14n1.14 
Stevenson, B. (2015). Sexuality in transition planning: Annotated bibliography. Charlotte, NC: National Technical Assistance Center on Transition.

Stangle, J. (2019). Family life and sexual health (FLASH) lesson plans for special education. Seattle, WA: Seattle School District No. 1 and The County of King. Retrieved from https://www.kingcounty.gov/depts/health/locations/family-planning/education/FLASH/sp ecial-education.aspx.

Test, D. (2016). Evidence-based practices and predictors in secondary transition: What we know and what we still need to know. Charlotte, NC: National Technical Assistance Center on Transition.

Test, D. W., Fowler, C. H., Richter, S. M., White, J., Mazzotti, V., Walker, A. R., Kohler, P., \& Kortering, L. (2009). Evidence-based practices in secondary transition. Career Development for Exceptional Individuals, 32(2), 115-128. https://doi.org/10.1177/0885728809336859

Trusty, J., \& Brown, D. (2005). Advocacy competencies for professional school counselors. Professional School Counseling, 8, 259-265.

U.S. Department of Education (2016). The State of Racial Diversity in the Educator Workforce. Washington D.C. Retrieved from https://www2.ed.gov/rschstat/eval/highered/racial-diversity/state-racial-diversity-workfor ce.pdf.

Welcoming Schools (2019). Great diverse children's books with transgender, non-binary, and gender expansive children. Retrieved from

https://assets2.hrc.org/welcoming-schools/documents/WS_Diverse_Picture_Books_Trans gender_Non-Binary.pdf

Wilke, N., \& Wilke, D. (2010) Identity, disability, and sexuality: Reflections from a son and his father. Impact, 23(2), 1, 34-35. 